\title{
Play, Playbour or Labour? The Relationships between Perception of Occupational Activity and Outcomes among Streamers and YouTubers
}

\author{
Maria Törhönen \\ Tampere University \\ maria.torhonen@uta.fi
}

\author{
Lobna Hassan \\ Hanken School of \\ Economics \\ lobna.hassan@hanken.fi
}

\author{
Max Sjöblom \\ Tampere University \\ max.sjoblom@tut.fi
}

\author{
Juho Hamari \\ Tampere University \\ juho.hamari@tut.fi
}

\begin{abstract}
The increasing digitalization and gamification of different aspects of our lives has blurred the line between what we consider work and play. Therefore, our productivity may increasingly depend on how we negotiate and view our occupations and work. Through an online survey $(n=382)$, this study examines the relationship between the perception of online video content creation as either work, play or equally as both, and the activities and income of these video content creators (streamers and YouTubers). The results indicate that those who view their content creation as work had the highest levels of activity and income, whereas those who associated their content creation with play, earned more income than those who regard their content creation equally as play and work. The results demonstrate the emergence of new forms of digital entrepreneurial practices in the workoriented group, but also the highlight the increasing workification of our play activities.
\end{abstract}

\section{Introduction}

The development of digital technology and the information society has had a significant impact on our working environments and cultures. Technology has advanced our work and communication practices beyond the borders of physical location, but has also provided us with the ability to introduce work into our free time and vice versa. This transition is exemplified in new forms of online work, such as the gig economy (e.g. Uber), sharing economy (e.g. Airbnb) and crowdsourcing (e.g. Wikipedia). But it is also evident in practices that aim to either merge play with work, such as gamification [1,2], or merge work with play such as playbour [3-6].

Therefore, the attitude and perception we hold towards our occupation activities might have a strong effect on our productivity. For example, if an activity were perceived as work, engagement with it would usually be expected to be serious and professional albeit not intrinsically motivating. On the other hand, if an activity is perceived as leisure, engagement with it could often be characterized by playfulness and the pursuit of enjoyment albeit possibly lacking a serious focus. What is relevant behaviour in one context may not be relevant in another. Therefore, understanding how we perceive different activities is of high importance, in order to understand how we engage with them and what outcomes we expect from them.

Content creation in digital and social media formats is often considered a leisure activity, where individuals produce and share content presumably in their free time, in order to connect with their social networks and to explore their creativity [7]. It is an activity that may lead to enjoyment and a feeling of sociability among other outcomes [7]. However, as digital and social media develop and become more integrated into our lives, the digital economy around an individual content creator and their content has begun to evolve.

This has been particularly evident in video content creation, or personal broadcasting activities, through digital platforms such as YouTube and Twitch that have begun to develop sophisticated monetisation systems and commercial benefits for their content creators. The introduction of direct income and commercial incentives to this activity has led to the increasing professionalisation of this type of personal broadcasting. Practices, such as scheduling, timemanagement and risk-taking, which are often associated with work, are becoming more common within the activity. This has led to an increasing merger of work and play within personal broadcasting activities. Therefore, these new forms of online work provide opportune avenues to research how people view and negotiate their work in the internet era.

The purpose of this research is to understand how personal broadcasters perceive their video content creation and how that perception correlates with their activities and the kinds of outcomes they gain from their content creation. Data was collected through an online survey $(\mathrm{N}=382)$ and was analysed in SPSS. The results allow us to examine this modern form of digital labour in relation to our traditional political economy understanding of work and labour. The results also provide possible opportunities for 
personal broadcasters to renegotiate their place in this digital "work" environment.

\section{Background}

\subsection{The digital workplace and gamification}

For the last decades, the complex relationship of work and leisure has been examined in conjunction with each other [8], in the context of work-family balance $[9,10]$, overall work-life balance [11,12], and the perceptions of an activity as leisure or as work $[13,14]$. However, more recently research has begun to focus more on the digitalisation of our working environments and the benefits of gameful and playful experiences in the workplace.

As the reach of games expanded into our modern society, culture and practices [15], we witnessed the exponential growth of the gaming industry that went hand in hand with the gamification of our modern cultural practices and work [16,17]. Gamification attempts to redesign processes and practices through game design so that tedious and repetitive activities become more perceptually enjoyable [1,2]. Hence, gamification has been employed to encourage positive behavioural change such as increased learning in educational contexts [18], enhancement of healthy personal habits [19] and improved productivity in the workplace and work practices [20]. While gamification does lead to enjoyable work experiences and improvements in individual and organizational productivity, as pointed out by most of the empirical research on the gamification of work $[1,21,22]$, it has also led to increasing merger of work and leisure.

\subsection{Digital labour, playbour and the workification in the media industry}

Ever since the emergence of broadcasting media, there has been an ongoing debate about the increasing merger of work like elements into leisure, and the commodification or workification of media consumption [23-27]. The debate has been deeply rooted into our existing understanding of the political economy and commercial media that have emphasised the relationship of labour and its direct economic value [28-30]. For centuries, labour has been equated in monetary value, which has been the subjective norm for the generations before us. However, the emergence of digital media formats such as television and later on, the internet, have transformed our underlying perception of labour by associating it with other types of rewards and gratifications such as enjoyment, entertainment and information [31-35].

The emergence of digital outlets and services has also resulted in the development of the digital economy, which combines elements from the postmodern cultural economy and the information industry [36]. In the digital economy, the prior identifiers of labour have become debatable as cultural artefacts and information have become a currency in their own right [37]. With the development of new digital media formats, especially services such as social media, our media consumption has also transformed into active digital prosumption [38-41], where the consumer also becomes a producer of digital content. Prosumer as a term refers to those individual content creators who are consumers, yet simultaneously produce content without direct incentive or association to a commercial entity [42]. The notion of a prosumer aims to define the blurring relationship between the producer of content and the consumer of content, which is evident in digital environments.

This type of prosumerism has become a typical activity for digital natives [43], an integrated part of modern life that provides a two-way communicative environment as well as a creative outlet for individuals, but also a facilitator of hybrid forms of work and play, playbour and digital labour.

The term, and concept, of digital labour has been associated with different activities within digital formats and services [24,25,36], whereas playbour has often been associated with the gaming culture $[3,4,6,44]$. The basis for this type of labour relies on the prosumption of media content in digital formats, which is considered to generate value [43] through e.g. identifier data and targeted advertising. Although the commodifying or exploitative nature of this labour is a constant discussion among scholars [25,45], many have argued that the prosumption culture as well as the development of the digital economy has given our informative and communicative labour a market value $[24,37]$. However, the digital economy has also begun to transform into a new innovative version of the traditional labour economy, by allowing the prosumers of content the ability to gain direct monetary value from their activities. It is hence strongly evident that in addition to gamification, where work is becoming more like play, play is also becoming more like work. There is a transformation of playful, leisure activities, towards more professional characteristics of which a prominent example is personal broadcasting (e.g. vlogging, live streaming, game streaming).

\subsection{Personal broadcasting and content creation}

Personal broadcasting consists of the production of video content by private individuals, and the distribution of said content through one or multiple commercial digital video sharing services such as YouTube or Twitch. For better understanding of this study and the analysed data, it is important to distinguish the labour of individual content creators 
from commercial entities, as the nuances of digital labour are most evident in the labour conducted by private individuals. These types of individuals are not directly associated with any commercial entity, and generate video content in their private channels, but may work in cooperation or partnership with brands and organisations. Table 1 provides further examples of personal broadcasters and commercial video content creators.

Table 1. Examples of private and commercial video content

\begin{tabular}{|c|c|c|c|c|c|}
\hline Example & Platform & Entity & Content & Content production & Subscribers/followers \\
\hline PlayStation & YouTube & Commercial & Commercial content & $\begin{array}{l}\text { Professionally } \\
\text { produced }\end{array}$ & 6.7 million \\
\hline $\begin{array}{l}\text { Jenna } \\
\text { Marbles }\end{array}$ & YouTube & $\begin{array}{l}\text { Private } \\
\text { individual }\end{array}$ & $\begin{array}{l}\text { Personal use/content, } \\
\text { commercial partnership } \\
\text { content }\end{array}$ & Self-produced & 17.8 million \\
\hline PlayStation & Twitch & Commercial & Commercial content & $\begin{array}{l}\text { Professionally } \\
\text { produced }\end{array}$ & 233,000 \\
\hline Ninja & Twitch & $\begin{array}{l}\text { Private } \\
\text { individual }\end{array}$ & $\begin{array}{l}\text { Personal use/content, } \\
\text { commercial partnership } \\
\text { content }\end{array}$ & Self-produced & 250,000 \\
\hline
\end{tabular}

Personal broadcasting as an activity begun to gain popularity in the mid 2000's with the emergence of the video sharing platform, YouTube. YouTube provided the opportunity for anyone to "broadcast yourself" and provide pre-recorded video content to the world through the internet. This personal broadcasting activity was furthered through the development of digital technology, as live broadcasting, or streaming, was introduced to the prosumers through streaming services, such as Twitch and YouTube live. The culture of personal broadcasting has rapidly grown to represent a variety of topics and personalities.

Live streaming as a phenomenon and technology has furthered the incorporation of personal broadcasting into everyday life. The integration of live-streaming functionalities to popular social media services such as Instagram and Facebook has made it more approachable for individuals to live broadcast their activities, but it has also promoted new forms of digital professions and celebrity. For example, game streaming has provoked new forms of online interaction through services such as Twitch, and endorsed digital careers such as "game streamer" [46], "professional gamer" or "esports player" [47,48]. By making the activity more approachable for individuals, live streaming has made the dream of online celebrity even more tangible, and increased the culture of personal broadcasting. It has also affected the way we perceive this activity as work or as leisure.

A novice personal broadcaster is often not compensated for their video content or activities and research has found that, similarly to other social media content creation [7], personal broadcasting is primarily intrinsically motivated [31]. However, as the culture and the digital economy around this activity has developed, the possibilities to gain an income from the activity have increased and personal broadcasting has gained more entrepreneurial like characteristics such as a level of risk-taking [49] and ambiguity [50,51].
The economy of this digital content creation activity revolves heavily around the attention of the viewers and the audiences a personal broadcaster can gain for their content. In this way the activity has begun to emphasize the characteristics of the attention economy [52-54], where the attention of the viewers is commodified and establishes a certain type of market value for the attention of the viewers. Although this attention of the viewers is, at best scarce, the digital landscape provides a global stage for personal broadcasters, with the potential to attract the attention of millions of people.

This potential combined with the allure of this leisure activity continues to attract more individuals towards the activity itself. Due to this increasing popularity of personal broadcasting and the demand for more diverse content, video sharing services have begun to develop their own digital economies, and reward the active and popular content creators for their activities through sophisticated loyalty programmes, that offer access to direct monetisation such as advertising and paid subscription services. However, in addition to these platform specific monetisation services, personal broadcasters are also increasingly involved in influencer marketing activities [55], which consist of paid marketing and partnerships deals with brands and organisations. Through these commercial developments, the activity of personal broadcasting has begun to combine some of the elements from our understanding of the waged economy and capitalism, but also generate new concepts of digital entrepreneurship and a type of intrinsic wage.

In this study, we aim to examine how the perception of personal broadcasting as work, play or as playbour, affects the activity levels and income of a personal broadcaster. We consider that personal broadcasters who do perceive the activity as play, are more likely to be motivated by gratifications previously associated with the use of YouTube [31] and digital content creation overall [7], such as 
enjoyment, entertainment and social interaction, which would further the engagement with the activity. Therefore, we hypothesise (H1) that a play-oriented perception will be associated with higher levels of activity when compared with those having a workorientation. As previous research has also indicated that achievement and goal-oriented behaviour [5658] has been associated with a work-oriented mentality e.g. entrepreneurship [58-60], we also hypothesise $(\mathrm{H} 2)$ that a work-oriented perception will be associated with higher levels of income than those having a play-orientation. Finally, we cautiously hypothesise (H3) that a perception of the activity as playbour will be associated with highest levels of income and activity, as these individuals may benefit from both intrinsic and extrinsic motivational forces simultaneously. However, it may also be possible that the combination is conflicting in a way that prevents either orientation to fully flourish.

\section{Methods and data}

This study is based on data that was collected through an online survey during 2017. The survey was distributed through various digital channels such as Facebook groups and subreddits related to specific video content genres and distribution services. Various personal broadcasters were also approached through email and messaging services of platforms such as YouTube, Twitch and Vidme (closed in 2017). The final sample consisted of 382 video content creators, with more specific demographic information presented in Table 2. work or play. The responses were given on a 7-point Likert scale, where each response item on the scale reflected a specific experience of the activity as work or fun. For this analysis, the average value of the responses to the provided statements were divided into the three categories, the work-oriented group, the play-oriented group and the playbour group. Each group directly identified with one specific statement on the scale $($ Work $=1$, Playbour $=4$, Play $=7$ ), but in order to ensure a representative group for each orientation, the cut off places for the work group was $<3.75$ and for the play group $>4.25$.

The analysis was constructed around these categorical variables, which were used to measure four dependent variables. The dependent variables used in the study measured the amount of months that the personal broadcaster had been active in their video content creation activities, the estimated hours they spend on producing and distributing their video content per week, the average hours they spend promoting their video content on other social media platforms and the total income they gained from the activity. The respondents provided their answers as estimates based on a list of provided frequencies, out of which the maximum value was used to interpret the data.

The data was analysed through a one-way analysis of variance (ANOVA). In order to assure the validity of the ANOVA, the data was grouped into three groups with independence of observation [61], and homogeneity of variance was tested through a Levene's test [61,62]. The significance of results within and between groups was examined using a post-hoc Tukey's test.

Table 2. Demographic information

\begin{tabular}{|c|c|c|c|c|c|c|c|}
\hline & & $\mathbf{N}$ & $\%$ & & & $\mathbf{N}$ & $\%$ \\
\hline \multirow[t]{4}{*}{ Gender } & Male & 280 & $73.6 \%$ & Employment & Part-time & 51 & $13.2 \%$ \\
\hline & Female & 97 & $25.1 \%$ & & Full-time & 128 & $33.7 \%$ \\
\hline & Other & 5 & $1.3 \%$ & & Student & 135 & $35.5 \%$ \\
\hline & & & & & Unemployed & 63 & $16.3 \%$ \\
\hline \multirow[t]{6}{*}{ Age } & $<17$ & 31 & $8.8 \%$ & & Retired & 5 & $1.3 \%$ \\
\hline & $18-24$ & 163 & $43.0 \%$ & & & & \\
\hline & $24-34$ & 128 & $33.2 \%$ & $\begin{array}{l}\text { Primary video } \\
\text { format }\end{array}$ & Live-streams & 25 & $6.5 \%$ \\
\hline & $35-44$ & 37 & $9.6 \%$ & & $\begin{array}{l}\text { Pre-recorded video } \\
\text { content }\end{array}$ & 124 & $32.1 \%$ \\
\hline & $44>$ & 21 & $5.4 \%$ & & & & $61.4 \%$ \\
\hline & & & & & Both & 233 & \\
\hline \multirow[t]{3}{*}{ Income } & Yes & 174 & $46.1 \%$ & Geographic origin & US & 122 & $31.9 \%$ \\
\hline & No & 208 & $53.9 \%$ & & Finland & 149 & $39 \%$ \\
\hline & & & & & Other & 111 & $29.1 \%$ \\
\hline
\end{tabular}

Each respondent was presented with four statements (presented in Appendix A) related to their activity, that measured their perception of their activity as
In order to ensure the validity and reliability of the measurements, specific measures were also taken in the construction of the survey. The order of the items 
from the work and play scale was randomised in the online survey, in order to ensure that the respondents were unable to detect patterns between these items
[63]. This extra measure was also used to decrease the potential effect of common method bias [64]. Analysis was conducted using SPSS version 24.

Table 3. Comparison of means

\begin{tabular}{lrrrrr}
\hline & Sum of Squares & Mean Square & F & df & $p$ \\
\hline Production hours/week & $7,360,223$ & $3,680,111$ & 11.240 & 2 & 0.000 \\
Tenure (in months) & $1,699,763$ & 849,881 & 0.801 & 2 & 0.405 \\
Social media hours (avg) & $1,843,609$ & 921,805 & 3.997 & 2 & 0.019 \\
Total income (\$) & $15,285,480,111$ & $7,560,721,913$ & 7.444 & 2 & 0.001 \\
\hline
\end{tabular}

\section{Results}

As seen in Table 3, the mean comparison of the three groups showed interesting differences between the groups. However, when examining these results through one-way ANOVAs, the difference between groups pertaining to production hours/week ( $\mathrm{p}<$ $0.001)$, average social media hours $(\mathrm{p}=0.019)$ and total income $(p=0.001)$, were clearly significant. The findings related to the tenure $(\mathrm{p}=0.405)$ variable were found insignificant based on the results of the oneway ANOVA seen in Table 4.

The findings of the study were further analysed using the Tukey's post-hoc HSD test to examine the significance of the differences between specific groups across the dependent variables, as seen in table 5 .

Significant differences were observed between the production hours of the work and play group $(\mathrm{p}<$ 0.001 ) and the playbour and play group ( $\mathrm{p}=$ $0.008)$. For total income, significant results were found between work and playbour group $(p=0.003)$ and the work and play groups $(\mathrm{p}=0.001)$. There were no significant findings found between the groups related to tenure or average social media hours.

\section{Discussion/Limitations/Conclusion}

\section{1. "The Workers"}

Examining the results of the study, various interesting findings emerge related to the perception of personal broadcasting as work. It seems that individuals who perceive the activity more as work, are the ones who spend the most hours per week on video content creation itself $(\mathrm{M}=25.00 \mathrm{~h})$, as well as the most average time on personal broadcasting related social media activities $(\mathrm{M}=11.88 \mathrm{~h})$. Additionally, they appear to be earning the most income on average out of the examined groups $(\mathrm{M}=\$ 774.85)$, therefore our hypothesis (H2) was not rejected. Despite being the most active in their broadcasting and the highest earners of the three groups, individuals who perceive personal broadcasting as work are not the ones with the most experience from these activities $(\mathrm{M}=34.21$ months). The findings related to this group indicate that individuals, who identify the activity as work, may be taking on a work-like mentality and a strategic approach to it, which is reflected in their high levels of production as well as income. While the traditional approach of political economy has associated work with direct income $[29,30]$, it could be argued that in this type of activity, income becomes the element that transforms play into work, rather than being just the outcome of such work. Interestingly, the workoriented group seems to convey a new, emerging form of digital entrepreneurial work within personal broadcasting, where individuals voluntarily professionalise their leisure activities and express goal-oriented behaviour as well as motivations for achievement and self-development, previously associated with entrepreneurial work $[49,58-60,65]$. Similar findings have also been reported when analysing worker types in online environments such as collaborative crowdsourcing [66].

Table 4. One-way ANOVA

\begin{tabular}{llllll}
\hline & & $\begin{array}{l}\text { Production } \\
\text { hours/week }\end{array}$ & $\begin{array}{l}\text { Tenure } \\
\text { (months) }\end{array}$ & $\begin{array}{l}\text { Social media } \\
\text { hours }(\mathbf{M})\end{array}$ & Total income (\$) \\
\hline Work & Mean & 25.00 & 34.21 & 11.88 & 774.85 \\
& N & 48 & 48 & 48 & 48 \\
& Std. Deviation & 19.46 & 30.363 & 18.04 & 1999.79 \\
Eq. Work & Mean & 20.74 & 33.95 & 10.91 & 145.76 \\
and Play & N & 66 & 66 & 66 & 66 \\
& Std. Deviation & 21.28 & 32.977 & 21.30 & 587.66 \\
Play & Mean & 13.28 & 38.67 & 6.55 & 179.11 \\
& N & 268 & 268 & 268 & 268 \\
& Std. Deviation & 16.97 & 32.858 & 12.64 & 818.15 \\
\hline
\end{tabular}


Table 5. Tukey's post-hoc HSD test results

\begin{tabular}{|c|c|c|c|c|}
\hline Dependent variable & & & Mean Difference (I-J) & $\mathbf{p}$ \\
\hline \multirow[t]{6}{*}{ Production hours/week } & \multirow[t]{2}{*}{ Work } & Equal & 4.258 & 0.430 \\
\hline & & Play & $11.724 *$ & 0.000 \\
\hline & \multirow[t]{2}{*}{ Equal } & Work & -4.258 & 0.430 \\
\hline & & Play & $7.466^{*}$ & 0.008 \\
\hline & \multirow[t]{2}{*}{ Play } & Work & $-11.724 *$ & 0.000 \\
\hline & & Equal & $-7.466^{*}$ & 0.008 \\
\hline \multirow[t]{6}{*}{ Tenure (months) } & \multirow[t]{2}{*}{ Work } & Equal & 254 & 0.999 \\
\hline & & Play & -4.461 & 0.657 \\
\hline & \multirow[t]{2}{*}{ Equal } & Work & -254 & 0.999 \\
\hline & & Play & -4.714 & 0.544 \\
\hline & \multirow[t]{2}{*}{ Play } & Work & 4.461 & 0.657 \\
\hline & & Equal & 4.714 & 0.544 \\
\hline \multirow{6}{*}{ Social media hours (avg) } & \multirow[t]{2}{*}{ Work } & Equal & 966 & 0.940 \\
\hline & & Play & 5.326 & 0.066 \\
\hline & \multirow[t]{2}{*}{ Equal } & Work & -966 & 0.940 \\
\hline & & Play & 4.361 & 0.093 \\
\hline & \multirow{2}{*}{ Play } & Work & -5.326 & 0.066 \\
\hline & & Equal & -4.361 & 0.093 \\
\hline \multirow[t]{6}{*}{ Total income (\$) } & \multirow[t]{2}{*}{ Work } & Equal & $629.097 *$ & 0.003 \\
\hline & & Play & $595.746^{*}$ & 0.001 \\
\hline & \multirow[t]{2}{*}{ Equal } & Work & $-629.097 *$ & 0.003 \\
\hline & & Play & -33.351 & 0.969 \\
\hline & \multirow{2}{*}{ Play } & Work & $-595.746^{*}$ & 0.001 \\
\hline & & Equal & 33.351 & 0.969 \\
\hline
\end{tabular}

This strategic and work-like mentality towards personal broadcasting can also be seen in the high levels of social media activity that this work-oriented group engages in. Personal broadcasters often utilize this type of multichannel approach as a promotional tool, which enhances their visibility as well as their overall digital presence and brand. At its core, the attention economy relies on capturing the attention of as many individuals as possible for as long as possible $[52,53]$. With social media as a promotional tool, personal broadcasters can attract more viewers and audiences for their content, which can be associated with a higher income. This could further explain why this group of individuals seems to be earning the most on average.

The results of this study also reveal the strenuous nature of this activity. As the overall sample of this study indicates, the majority of the respondents are also engaged in full-time work or studies, which implies that personal broadcasting, may take up most of their free time. This level of work-like activity may lead to negative effects such as exhaustion and even depression, which have already been reported by some popular YouTubers and live-streamers [46,67] Similar negative traits have been associated with entrepreneurial work $[58,68]$. It should be noted that even for those personal broadcasters, who create video content as their full-time employment, this level of activity would constitute nearly half of the weekly average working hours, which also excludes all promotional and administrative or organisational tasks, that are also associated with this type of independent work. Therefore, some form of organisation or recognition for this type of profession would be required, in order to maintain the well-being of these type of new workers.

\section{2. "The Playbourers"}

Interestingly enough, it is the group that considers the activity equally as work and play, or playbour, who gains the least amount of income from their activities ( $M=\$ 145.76)$. Although this group is almost as active in their content creation activities as the work oriented group by investing almost the same number of hours on the activity itself $(M=20.74)$ as well as on related social media activities $(M=10.91)$, their income levels are less than a fourth of that earned by the work-oriented group. This partly rejects our hypothesis (H3) and seems to assert our assumption about the conflict this perception may cause.

It appears that this "playbourer" group may lack a certain focus or strategy from their personal broadcasting activities, which has resulted in more time spent on the activity itself, but less concrete outcomes gained from it. This lack of focus and strategy may be affected by the longer tenure within the activity, during which the professional elements of the activity have begun to developed and be more available. In order to better understand this aspect, it would be valuable to further examine video content creators with different tenure among the activity and 
their perceptions of professionalisation of the activity and the effects of the development of monetisation in this activity. On the other hand, personal broadcasting is a creative activity. Technical and professional skills needed to perform the activities may have been acquired after a certain time of engaging with it and the increased time spent on broadcasting does not necessarily lead to the development of skills that are of direct value to income generation. It would be of value for further studies to examine this possible correlation between creativity, experience with an activity, and its outcomes.

The obtained findings about this group may also reflect the difficult nature of this type of digital labour and online entrepreneurship, where risk-taking [49] and ambiguity [50] of the activity are heightened, and clear objectives and aims, which are often associated with traditional work environments may be missing. The independent nature of this type of work, and the highly competitive environment of the video sharing platforms, may affect those content creators, who approach the activity without a clear focus or a strong passion for the activity.

In order to better understand the characteristic of this type of work, future research should be focused on the work-oriented group to define the nature of this type of digital labour. Finally, these obtained results for the group divided between work and play further emphasize how possible blurring of lines between work and play in digital environments could reduce worker productivity, income, and possibly overall well-being as it has in traditional work environments [69]. Well-being in particular was not examined by our study and future research is encourage to compare levels of subjective wellbeing between personal broadcasters depending on their perceptions of the activity.

\section{3. "The Hobbyists"}

The final group examined in this research and incidentally, the largest group identified in our sample, is the group of content creators who identified the activity as more play than work. This play-oriented group has the longest experience from the activity (M $=38.67$ months). However they seem to be by far, the least active group in regards to their activities, as they spend nearly half the amount of time on the production and distribution of video content $(\mathrm{M}=$ $13.28 \mathrm{~h})$ and on social media activities $(\mathrm{M}=6.55 \mathrm{~h})$, compared to the work and playbour groups. This rejects our hypothesis (H1), although the group could be considered as the most dedicated group based on their tenure.

This finding related to the activity levels of the play-oriented group is interesting, since the association with leisure and play, could be considered to lead to higher engagement with the activity itself. When examining previous research on hobbies and free time, we do however see similar findings, where the element of "free time" [70] is associated with various activities and is allocated a specific time from each day or week [71]. For example, an average US gamer would spend 7 hours [72] per week on online gaming, whereas an average person seems to spend around 135 minutes a day on social media [73]. This finding may also indicate that this group has a more casual attitude towards the activity, where it is merely one part of an individual's day, whereas the workoriented group clearly has a more dedicated attitude towards the activity, where they are investing much more time on it.

As it can be argued that as this group perceives this activity as a leisure activity, it may be motivated by similar motivations as other types of digital content creation [7] or the consumption of digital video content [74], such as enjoyment, entertainment as well as socialisation. Perceiving an activity as a play or leisure activity has also been found to be associated with intrinsic motivators [13].

This underlying heightened appreciation of intrinsic and hedonic motive, may lead to less focus on the income that can be derived from the activity, which could be demonstrated in lower levels of income for this group. However, the results of this study do indicate that this play oriented group is still likely to earn more income $(\mathrm{M}=\$ 179.11)$ from their activity than the playbour group. It may be that the intrinsic and hedonic experiences gained from the activity itself, is somewhat reflected in the produced content as a more enjoyable or entertaining experience for the consumer. This could attract more viewers to the content, as viewers have also been examined to be motivated by entertainment and enjoyment [74], and lead to the acceleration of the attention economy and further income for the content creator.

The average level of income reported in this study indicates that although the income level of the playoriented group is not as high as that of the workoriented group, there appears to be potential to generate income through this activity while engaging with it as pure play. In a way, this finding contradicts some of the ongoing debate about digital labour and commodification of our digital activities, as the personal broadcaster is gaining compensation from their activities, which they consider as play. Interestingly, when examining this finding, the traditional ways in which we perceive work or labour $[28,30,75]$, and the practice of gamification $[22,76]$, it could also be argued that through this activity, we are trying to workify play, where this type of leisure activity is taking on characteristics of work, but not altering the way the activity itself is perceived or the gratifications derived from it. This type of workification further alters our understanding of work and the way the modern worker approaches work-like tasks, it also provides potential avenues for future 
research and practical use, in for example further development of our gamification practices.

\section{Limitations}

The data for this study was collected through an online survey, which provides a specific vantage point on an individual's perceptions and views of reality [77]. As this study is focused on understanding perceptions of personal broadcasting in relation to specific metrics that indicate levels of activity and income, a survey was considered a suitable method for data collection. Nonetheless, future research is highly recommended to employ a wider array of research methods in investigating personal broadcasting from different vantage points such as through qualitative surveys, focus groups or interviews.

We also do acknowledge the specific limitations of using online surveys in data collection. As an online survey relies on self-reporting of activities in an unsupervised environment, we have to take into account the possibility of common-method bias [78] and acknowledge that the activities measured in this study are based on estimates and self-reported values. The common-method bias was addressed by utilizing a variety of distribution sources for the survey and a randomized order for items in the survey. Ethnographic observation methods could provide a more detailed insight into these activities, but due to the intensity of the behaviour, and its private nature, it may not provide accurate results either.

This study grouped together pre-recorded content creators and live-streamers. While small nuanced differences may exist between the two groups, many of the study respondents reported to engage in both live-streaming and pre-recorded video content creation. Hence, we examined the overall production behaviour of the respondents instead of examining specific broadcasting forms or services. It should also be noted that the sample is heavily male-focused, which may limit our findings. The majority of the respondents were located in the US and Finland, which does provide variation in terms of the western culture of personal broadcasting, but it should be noted that further research should be conducted in eastern cultures, e.g. in the Chinese market, where the culture of personal broadcasting is different and utilizes local services.

The three groups examined in this research were different sizes, but each group had enough respondents for them to be compared in this study. Some of our findings were found insignificant through further tests and therefore cannot be considered conclusive.

This work was supported by the Media Industry Research Foundation of Finland (grant number 20180084), the Finnish foundation for economic education (grants number 10-5562 and 12-6385),
Business Finland (5479/31/2017 and 40009/16) as well as project partners, Satakunnan korkeakoulusäätiö and its collaborators, and Academy of Finland (Center of Excellence in Game Culture Studies).

\section{References}

[1] Huotari K, Hamari J. A definition for gamification: anchoring gamification in the service marketing literature. Electron Mark. 2017;27(1):21-31.

[2] Deterding S. The lens of intrinsic skill atoms: A method for gameful design. Vol. 30, HumanComputer Interaction. 2015. p. 294-335.

[3] Kücklich J. Precarious Playbour : Modders and the Digital Games. Fibreculture [Internet]. 2005;(5):1-8. Available from: http://five.fibreculturejournal.org/fcj-025precarious-playbour-modders-and-the-digitalgames-industry/

[4] Sotamaa O. On modder labour, commodification of play, and mod competitions. First Monday. 2007;12(9)

[5] Sotamaa O. Play, Create, Share? Console Gaming, Player Production and Agency. Fibreculture J [Internet]. 2010;(2000):1-13. Available from: http://sixteen.fibreculturejournal.org/play-createshare-console-gaming-player-production-andagency/

[6] Ferrer-Conill R. Playbour and the Gamification of Work: Empowerment, Exploitation and Fun as Labour Dynamics. In: Technologies of Labour and the Politics of Contradiction. 2018.

[7] Matikainen J. Motivations for content generation in social media. J Audience Recept Stud. 2015;12(1):41-58.

[8] Blocher DH, Siegal R. Toward A Cognitive Developmental Theory of Leisure and Work. Couns Psychol. 1981;9(3):33-44.

[9] Carlson DS, Grzywacz JG, Zivnuska S. Is workfamily balance more than conflict and enrichment? Hum Relations [Internet]. 2009;62(10):1459-86. Available from: http://journals.sagepub.com/doi/10.1177/0018726 709336500

[10] Grzywacz JG, Carlson DS. Conceptualizing Work-Family Balance: Implications for Practice and Research. Adv Dev Hum Resour. 2007;9(4).

[11] Parkes LP, Langford PH. Work-life balance or work-life alignment? J Manag Organ. 2008;14(3):267-84.

[12] Kalliath T, Brough P. Achieving work-life balance. Journal of Management and Organization. 2008;14(3):224-6.

[13] Juniu S, Tedrick T. Leisure or work?: Amateur and professional musicians.. J Leis Res [Internet]. 1996;28(1):44. Available from: https://www.nrpa.org/globalassets/journals/jlr/199 6/volume-28/jlr-volume-28-number-1-pp-4456.pdf

[14] Juniu S. Downshifting: Regaining the essence of leisure. J Leis Res [Internet]. 2000;32(1):69-73. Available from: https://www.nrpa.org/globalassets/journals/jlr/200 0/volume-32/jlr-volume-32-number-1-pp-69- 
73.pdf

[15] Vesa M, Hamari J, Harviainen JT, Warmelink H. Computer Games and Organization Studies. Organ Stud. 2017;38(2):273-84.

[16] Khaled R. Gamification and Culture. Gameful World Approaches, Issues, Appl. 2014;301-21.

[17] Raessens J. Playful identities, or the ludification of culture. Games Cult. 2006;1(1):52-7.

[18] Nah FF-H, Zeng Q, Telaprolu VR, Ayyappa AP, Eschenbrenner B. Gamification of education: A review of literature. In: 1st International Conference on HCI in Business, HCIB 2014 - Held as Part of 16th International Conference on Human-Computer Interaction, HCI International 2014 [Internet]. 2014. Available from: http://www.scopus.com/inward/record.url?eid=2s2.0-

84903729964\&partnerID=40\&md5=0f5ab38ae34 a9a1037dc69faa273b2e4

[19] Hamari J, Koivisto J. Working out for likes": An empirical study on social influence in exercise gamification. Comput Human Behav. 2015;50:333-347.

[20] Kumar J. Gamification at work: Designing engaging business software. In: Lecture Notes in Computer Science (including subseries Lecture Notes in Artificial Intelligence and Lecture Notes in Bioinformatics). 2013. p. 528-37.

[21] Hamari J, Koivisto J, Sarsa H. Does gamification work?--a literature review of empirical studies on gamification. Syst Sci (HICSS), 2014 47th Hawaii Int Conf [Internet]. 2014;3025-34. Available from:

http://ieeexplore.ieee.org/xpls/abs_all.jsp?arnumb er $=6758978$

[22] Warmelink H, Koivisto J, Mayer I, Vesa M, Hamari J. Gamification of the work floor: A literature review of gamifying production and logistics operations. Proc 51th Annu Hawaii Int Conf Syst Sci [Internet]. 2018;(January):10. Available from: http://hdl.handle.net/10125/50026

[23] Smythe DW. Communication: Blindspot of Western Marxism. Can J Polit Soc Theory. 1977;1(3):1-27.

[24] Terranova T. Free labour. In: Digital Labor: The internet as playground and factory. 2013. p. 33-57.

[25] Bermejo F. The Internet audience : constitution \& measurement [Internet]. Digital formations ; v. 35. 2007. x, 262 p. Available from: http://www.loc.gov/catdir/toc/ecip0617/20060224 50.html

[26] Fuchs C. The political economy of privacy on facebook. Telev New Media. 2012;13(2):139-59.

[27] Mosco V. The Political Economy of Journalism. Economia [Internet]. 2016;48:19. Available from: http://www.academia.edu/download/51081513/LI VRO_ECONOMIA_POLITICA_DO_JORNALI SMO1.pdf\#page $=20$

[28] Mosco V. The Political Economy of Labor. In: The Handbook of Political Economy of Communications. 2011. p. 358-80.

[29] Foley DK. The Political Economy of Postcrisis Global Capitalism. South Atl Q [Internet]. 2012;111(2):251-63. Available from: https://read.dukeupress.edu/south-atlanticquarterly/article/111/2/251-263/3579
Smith A, Hollander JH. Adam Smith 1776-1926. J Polit Econ. 1927;35(2):153-97.

[31] Khan ML. Social media engagement: What motivates user participation and consumption on YouTube? Comput Human Behav. 2017;66:23647.

[32] Rubin AM. An examination of television viewing motivations. Communic Res. 1981;8(2):141-65.

[33] Rubin AM. Television Uses and Gratifications : The Motivations. J Broadcast [Internet]. 2011;1:89-109. Available from: http://search.ebscohost.com/login.aspx?direct=tru $\mathrm{e} \& \mathrm{db}=\mathrm{cax} \& \mathrm{AN}=50038704 \&$ site $=$ ehost -

live $\&$ scope $=$ site

[34] Nov O. What motivates Wikipedians? Commun ACM [Internet]. 2007;50(11):60-4. Available from:

http://portal.acm.org/citation.cfm?doid=1297797. 1297798

[35] Nov O, Naaman M, Ye C. Analysis of participation in an online photo-sharing community: A multidimensional perspective. J Am Soc Inf Sci Technol. 2010;61(3):555-66.

[36] Scholz. Digital Labor. Digital Labor - The Internet as Playground and Factory. 2012. 98-111 p.

[37] Terranova T. Free Labor: PRODUCING CULTURE FOR THE DIGITAL ECONOMY. Soc Text [Internet]. 2000;18(2 63):33-58. Available from: http://socialtext.dukejournals.org/cgi/doi/10.1215/ 01642472-18-2_63-33

[38] Toffler A. The Third Wave - The Classic Study of Tomorrow [Internet]. Bantam, New York. 1980. 448 p. Available from: http://www.randomhousebooks.com/books/17910 2/

[39] Ritzer G. Focusing on the Prosumer. In: Prosumer Revisited [Internet]. 2010. p. 61-79. Available from: http://link.springer.com/10.1007/978-3-53191998-0_3

[40] Ritzer G. Prosumer Capitalism. Sociol Q. 2015;56(3):413-45.

[41] Fuchs C. Digital prosumption labour on social media in the context of the capitalist regime of time. Time Soc. 2014;23(1):97-123.

[42] Ritzer G, Jurgenson N. Production, Consumption, Prosumption: The nature of capitalism in the age of the digital "prosumer." J Consum Cult. 2010;10(1):13-36.

[43] Van Dijck J, Poell T. Understanding Social Media Logic. Media Commun. 2013;

[44] Sotamaa O. When the game is not enough: Motivations and practices among computer game modding culture. Games Cult. 2010;5(3):239-55.

[45] Jhally S, Livant B. Watching as Working: The Valorization of Audience Consciousness. J Commun. 1986;

[46] D'Anastasio C. For Twitch Streamers Who Spend Their Lives On Camera, It's Hard To Know When To Stop. Kotaku [Internet]. Available from: https://kotaku.com/for-twitch-streamers-whospend-their-lives-on-camera-i-1792351731

[47] Bányai F, Griffiths MD, Király O, Demetrovics Z. The Psychology of Esports: A Systematic Literature Review. J Gambl Stud. 2018;

[48] Tassi P. The U.S. Now Recognizes eSports Players 
As Professional Athletes. Forbes. 2013.

[49] Drucker PF. Innovation and Entrepreneurship. Innovation and Entrepreneurship. 2014.

[50] Knight FH. Profit and Entrepreneurial Functions. J Econ Hist. 1942;

[51] Emmett RB. The Economist and the Entrepreneur: Modernist Impulses in Risk, Uncertainty, and Profit. Hist Polit Econ. 1999;

[52] Simon $\mathrm{H}$ a. Designing organizations for an information-rich world. Comput Commun public Interes. 1971;72:37.

[53] Huberman BA. Social Computing and the Attention Economy. J Stat Phys. 2013;151(12):329-39.

[54] Huberman B a., Romero DM, Wu F. Social networks that natter: Twitter under the microscope. First Monday [Internet]. 2009;14(1):1-9. Available from: http://www.hpl.hp.com/research/scl/papers/twitter /twitter.pdf

[55] Abidin C, Ots M. The Influencer's dilemma: The shaping of new brand professions between credibility and commerce. "Media Branding Revised: Participative Audiences and their Consequences for Media Branding [Internet]. 2015;1-12. Available from: http://www.divaportal.org/smash/record.jsf?pid=diva2\%3A85003 $3 \&$ dswid $=473$

[56] McClelland DC. Human motivation. Motivation and Personality. 1987.

[57] McClelland DC. How Motives, Skills, and Values Determine What People Do. Am Psychol. 1985;

[58] Mcmullen JS, Sheperd DA. ENTREPRENEURIAL ACTION AND THE ROLE OF UNCERTAINTY IN THE THEORY OF THE ENTREPRENEUR. Acad Manag Rev. 2006;

[59] Korunka C, Frank H, Lueger M, Mugler J. The Entrepreneurial Personality in the Context of Resources, Environment, and the Startup ProcessA Configurational Approach. Entrep Theory Pract. 2003;

[60] Davidson E, Vaast E. Digital entrepreneurship and its sociomaterial enactment. In: Proceedings of the Annual Hawaii International Conference on System Sciences. 2010.

[61] Field A. Discovering Statistics Using SPSS. Sage Publication. 2009.

[62] Levene H. Levene test for equality of variances. Contrib to Probab Stat. 1960;

[63] Campbell D, Cook T. Quasi-experimentation: Design and analysis for field settings [Internet]. Skokie, IL: Rand McNally. 1979. 420 p. Available from: $\quad$ http://dickyh.staff.ugm.ac.id/wp/wpcontent/uploads/2009/ringkasan buku quasiexperimentakhir.pdf

[64] Podsakoff PM, MacKenzie SB, Lee J-Y, Podsakoff NP. Common method biases in behavioral research: a critical review of the literature and recommended remedies. J Appl Psychol [Internet]. 2003;88(5):879-903. Available from:

http://www.ncbi.nlm.nih.gov/pubmed/14516251

[65] McClelland DC, Burnham DH. Power is the Great Motivator. Harvard Business Review. 2003.

[66] Kazai G, Koolen M, Kamps J, Doucet A, Landoni
M. Overview of the INEX 2010 book track: Scaling up the evaluation using crowdsourcing. In: Lecture Notes in Computer Science (including subseries Lecture Notes in Artificial Intelligence and Lecture Notes in Bioinformatics). 2011.

[67] Alexander J. YouTube's top creators are burning out and breaking down en masse. Polygon [Internet]. 2018; Available from: https://www.polygon.com/2018/6/1/17413542/bur nout-mental-health-awareness-youtube-elle-millsel-rubius-bobby-burns-pewdiepie

[68] Boyd DP, Gumpert DE. Coping with entrepreneurial stress. Harvard Business Review. 1983.

[69] Ernst Kossek E, Ozeki C. Work-family conflict, policies, and the job-life satisfaction relationship: A review and directions for organizational behavior-human resources research. J Appl Psychol. 1998;

[70] Valtonen A. Rethinking Free Time: a Study on Boundaries, Disorders and Symbolic Goods. Aalto University; 2004.

[71] Olmsted A.D. Hobbies and Serious Leisure. World Leis Recreat. 1993;35(1):27-32.

[72] ESA. Essential Facts About the Computer and Video Game Industry [Internet]. 2018. Available from: http://www.theesa.com/about-esa/essentialfacts-computer-video-game-industry/

[73] Statista. No Daily time spent on social networking by internet users worldwide from 2012 to 2017 (in minutes) [Internet]. 2017. Available from: https://www.statista.com/statistics/433871/dailysocial-media-usage-worldwide/

[74] Sjöblom M, Hamari J. Why do people watch others play video games? An empirical study on the motivations of Twitch users. Comput Human Behav. 2017;75:985-96.

[75] Mosco V. The political economy of communication. The Political Economy of Communication. 2009. 1-268 p.

[76] Deterding S, Khaled R, Nacke L, Dixon D. Gamification: toward a definition. Chi 2011 [Internet]. 2011;12-5. Available from: http://gamification-research.org/wpcontent/uploads/2011/04/02-Deterding-KhaledNacke-Dixon.pdf

[77] Barker C, Pistrang N. Quality criteria under methodological pluralism: Implications for conducting and evaluating research. In: American Journal of Community Psychology. 2005.

[78] Straub D, Boudreau M-C, Gefen D. Validation Guidelines for Is Positivist. Commun Assoc Inf Syst. 2004;

\section{Appendix A.}

\begin{tabular}{llll}
\hline \multicolumn{4}{l}{ Items for the Work and Play scale } \\
\hline WP1 & $\begin{array}{l}\text { I think my } \\
\text { streaming }\end{array}$ & $\begin{array}{l}\text { Extremely serious } \\
\text { Extremely fun }\end{array}$ \\
WP2 & $\begin{array}{l}\text { activities } \\
\text { are.... }\end{array}$ & $\begin{array}{l}\text { Extremely instrumental } \\
\text { Extremely entertaining }\end{array}$ \\
WP3 & & Extremely work-related - \\
& & Extremely leisure-related \\
WP4 & & Extremely labour intensive - \\
& & Extremely relaxing \\
\hline
\end{tabular}

